\title{
Structures of Prosapogenins from Roots of Platycodon grandiflorum determined by Carbon-13 and Hydrogen-1 Nuclear Magnetic Resonance Spectroscopy
}

\begin{abstract}
The structures of four new prosapogenins (2-5) isolated from roots of Platycodon grandiflorum A. DC. have been elucidated using ${ }^{13} \mathrm{C}$ - and ${ }^{1} \mathrm{H}$-nuclear magnetic resonance spectroscopy.

Keywords_-Oleanene-type prosapogenins; Platycodon grandiflorum; C-13 and H-1 NMR; C-13 glucosidation shift; glucobioses; platycodigenin; polygalacic acid
\end{abstract}

The search for saponins and sapogenins having useful biological activities in a Chinese drug "Jieseng" (Japanese name: Kikyo), roots of Platycodon gradiflorum A. DC., has been continued in this laboratory." The structures of several sapogenins isolated were determined in recent years. ${ }^{1)}$ However, there was only reported the structure elucidation of platycodin$\mathrm{D}^{1)}$ and its prosapogenin, 3-O- $\beta$-D-glucopyranosylplatycodigenin $(\mathbf{1})^{2)}$ concerning saponins and prosapogenins of $P$. grandiflorum.

We have obtained prosapogenin methyl esters by alkaline hydrolysis of a hot-methanol extract of platycodi radix followed by methylation with diazomethane, and then separated

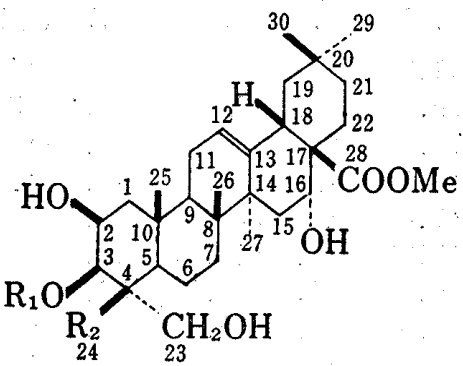

$\mathrm{R}_{1}$

1: $\beta$-D-glucopyranosyl (Glc)

2: $\beta$-laminaribiosyl (Lam)

3: $\beta$-gentiobiosyl (Gen)

4: $\beta$-D-glucopyranosyl (GIc) $\mathrm{Me}$

5: $\beta$-laminaribiosyl (Lam) Me

6: $\mathrm{H}$

7: $\mathrm{H}$

$\mathrm{Me}$

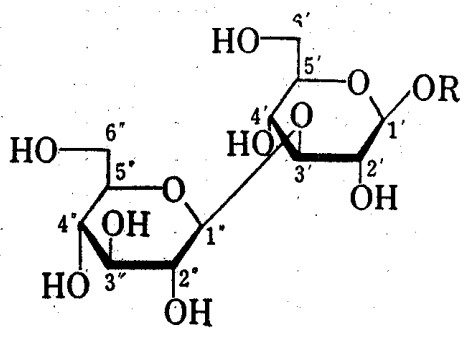

$\beta$-Lam

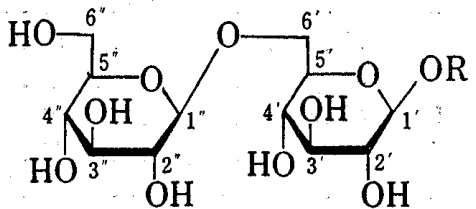

$\beta-\mathrm{Gen}$

$\mathrm{CH}_{2} \mathrm{OH}$

$\mathrm{CH}_{2} \mathrm{OH}$

$\mathrm{CH}_{2} \mathrm{OH}$

$\mathrm{Me}$

Chart 1

TABle I. Physical properties of Prosapogenin Methyl Esters (1-5)

\begin{tabular}{lccccc}
\hline \hline & 1 & 2 & 3 & 4 & 5 \\
\hline$m p$ & $213-219^{\circ}$ & $231-237^{\circ}$ & $209-218^{\circ}$ & $269-278^{\circ}$ & $244-248^{\circ}$ \\
$\operatorname{Rf} a)$ & 0.36 & 0.24 & 0.21 & 0.43 & 0.29 \\
Anal. & $\mathrm{C}_{37} \mathrm{H}_{60} \mathrm{O}_{12} \cdot$ & $\mathrm{C}_{43} \mathrm{H}_{70} \mathrm{O}_{17} \cdot$ & $\mathrm{C}_{43} \mathrm{H}_{70} \mathrm{O}_{17}$ & $\mathrm{C}_{37} \mathrm{H}_{60} \mathrm{O}_{11} \cdot$ & $\mathrm{C}_{43} \mathrm{H}_{70} \mathrm{O}_{16}$ \\
{$[\alpha] \mathrm{D}(\mathrm{MeOH})$} & $\mathrm{H}_{2} \mathrm{O}$ & $2 \mathrm{H}_{2} \mathrm{O}$ & $3 \mathrm{H}_{2} \mathrm{O}$ & $3 / 2 \mathrm{H}_{2} \mathrm{O}$ & $\mathrm{H}_{2} \mathrm{O}$ \\
& $+29.1^{\circ}$ & $+20.9^{\circ}$ & $+23.9^{\circ}$ & $+18.3^{\circ}$ & $+16.7^{\circ}$ \\
\hline
\end{tabular}

a) Solvent, $\mathrm{CHCl}_{3}-\mathrm{MeOH}-\mathrm{H}_{2} \mathrm{O}(30: 10: 1)$, double development.

1) For the history of the research and a leading ref., see A. Tada, Y. Kaneiwa, J. Shoji, and S. Shibata, Chem. Pharm. Bull. (Tokyo), 23, 2965 (1975).

2) T. Akiyama, O. Tanaka, and S. Shibata, Chem. Pharm. Bull. (Tokyo), 20, 1957 (1972). 
them into eight fractions by repeated column-chromatography. Compounds $\mathbf{1}-\mathbf{5}$ were thus isolated, crystallized, and characterized as listed in Table I.

We firstly examined $100-\mathrm{MHz}^{1} \mathrm{H}$ nuclear magnetic resonance (NMR) spectra of prosapogenin methyl esters $(\mathbf{1}-\mathbf{5})$ and methyl esters of known sapogenin from $P$. grandiflorum, ${ }^{1)}$ platycodigenin (6) and polygalacic acid (7), in $\mathrm{C}_{5} \mathrm{D}_{5} \mathrm{~N}$ as well as their peracetates (1a-7a) in $\mathrm{CDCl}_{\mathbf{3}}$ (see Table II) to find that the spectra of $\mathbf{1 - 3}$ have five angular methyl signals and resemble each other and that of 6 , and that those of 4 and 5 have six angular methyl signals and resemble each other and that of 7 . These results suggested aglycones of $1-3$, and 4 and 5 to be 6 and 7, respectively. Furthermore, from ${ }^{1} \mathrm{H}$ NMR data on the H-2 $\alpha$ (quartet) and $\mathrm{H}-3 \alpha$ (doublet) signals, all the prosapogenins mentioned here were also suggested to have 3-O-sugar moieties (see Table II).

TABLE II. Data on ${ }^{1} \mathrm{H}$ and ${ }^{13} \mathrm{C}$ Chemical Shifts ${ }^{a)}$ of Compounds $1-7$ in Pyridine- $\mathrm{d}_{5}$ and Peracetates in $\mathrm{CDCl}_{3}$ (in Parentheses) ${ }^{b}$ )

\begin{tabular}{|c|c|c|c|c|c|c|c|c|c|c|c|c|c|c|}
\hline & 6 & $(\mathbf{6 a})$ & 1 & (1a) & 2 & $(\mathbf{2 a})$ & 3 & $(\mathbf{3 a})$ & 7 & $(7 \mathbf{a})$ & 4 & $(\mathbf{4 a})$ & 5 & (5a) \\
\hline $\mathrm{H}-2 \alpha$ & 4.60 & $(5.41)$ & 4.95 & $(5.38)$ & 4.96 & $(5.35)$ & 4.85 & $(5.43)$ & 4.51 & $(5.42)$ & 4.78 & $(5.32)$ & 4.77 & $(5.34)$ \\
\hline $3 \alpha$ & 4.37 & $(5.03)$ & c) & $(3,72)$ & c) & $(3.54)$ & c) & $(3.58)$ & 4.22 & $(4.94)$ & c) & $(3.58)$ & c) & $(3.47)$ \\
\hline 24 & c) & (c) & c) & (c) & c) & (c) & c) & (c) & 1.36 & $(1.05)$ & 1.36 & $(0.97)$ & 1.35 & $(0.96)$ \\
\hline 25 & 1.67 & $(1.26)$ & 1.54 & $(1.15)$ & 1.54 & $(1.16)$ & 1.47 & (1.18) & 1.64 & $(1.26)$ & 1.62 & $(1.14)$ & 1.61 & (1.13) \\
\hline 26 & 0.95 & $(0.75)$ & 0.92 & $(0.72)$ & 0.92 & $(0.73)$ & 0.91 & $(0.73)$ & 0.97 & $(0.77)$ & 0.97 & $(0.73)$ & 0.95 & $(0.71)$ \\
\hline 27 & 1.72 & $(1.26)$ & 1.72 & $(1.22)$ & 1.72 & $(1.21)$ & 1.72 & $(1.21)$ & 1.72 & $(1.26)$ & 1.75 & $(1.21)$ & 1.75 & $(1.22)$ \\
\hline C-1 & 44.6 & $(41.8)$ & 45.0 & $(42.0)$ & 44.9 & $(42.0)$ & 45.1 & $(42.4)$ & 45.0 & $(41.7)$ & 44.2 & $(41.7)$ & 44.2 & $(41.8)$ \\
\hline 2 & 71.6 & $(69.3)$ & 69.3 & $(72.1)$ & 69.4 & $(72.1)$ & 68.5 & $(72.2)$ & 71.6 & $(69.6)$ & 70.3 & $(72.2)$ & 70.4 & $(72,1)$ \\
\hline 3 & 75.3 & (71.9) & 86.4 & $(80.6)$ & 86.3 & (79.9) & 87.7 & $(80.8)$ & 74.1 & $(72.0)$ & 83.8 & $(80.7)$ & 83.7 & $(80.3)$ \\
\hline 4 & 46.6 & $(43.7)$ & 48.0 & $(45,4)$ & 48.0 & $(45.5)$ & 46.5 & $(45.6)$ & 42.3 & $(40.1)$ & 42.8 & $(41.5)$ & 42.9 & $(41.5)$ \\
\hline 5 & 48.8 & $(47.6)$ & 48.0 & $(48.5)$ & 48.0 & (48.5) & 48.1 & $(48.7)$ & 49.1 & $(47.4)$ & 48.3 & $(48.0)$ & 48.2 & $(48.0)$ \\
\hline 6 & 19.1 & $(19.1)$ & 19.6 & $(19.6)$ & 19.5 & $(19.7)$ & 19.6 & $(19.7)$ & 18.6 & (17.7) & 18.3 & $(18.0)$ & 18.3 & $(18.0)$ \\
\hline 10 & 37.1 & $(36.7)$ & 37.6 & $(36.7)$ & 37.5 & $(36.6)$ & 38.0 & $(36.6)$ & 37.4 & $(36.7)$ & 37.2 & $(36.6)$ & 37.2 & $(36.6)$ \\
\hline 23 & 64.3 & $(62.8)$ & 63.8 & $(63.4)$ & 63.8 & $(63.3)$ & 63.6 & $(63.0)$ & 69.3 & $(65.5)$ & 66.5 & $(66.2)$ & 66.2 & $(66.2)$ \\
\hline 24 & 64.7 & $(63.9)$ & 66.3 & $(64.0)$ & 65.7 & $(64.0)$ & 67.7 & $(63.9)$ & 14.2 & (13.9) & 14.8 & (13.7) & 14.8 & $(13.7)$ \\
\hline 25 & 17.2 & (16.4) & 18.1 & $(16.5)$ & 18.0 & (16.4) & 18.8 & $(16.4)$ & 17.4 & $(16.6)$ & 17.4 & $(16.6)$ & 17.4 & (16.5) \\
\hline $1^{\prime}$ & & & 106.0 & $(102.2)$ & 105.5( & $102.2)$ & 106.0 & $(102.8)$ & & & 105.2( & $102.2)$ & 105.6 & (102.4) \\
\hline $2^{\prime}$ & & & 75.2 & $(71.2)$ & 74.1 & $(71.4)^{g)}$ & 75.0 & $(72.2)$ & & & 75.5 & $(71.5)$ & 74.2 & $(71.6)$ \\
\hline $3^{\prime}$ & & & 78.6 & (73.3) & 88.7 & $(78.8)$ & 78.0 & $(74.5)$ & & & 78.6 & $(73.3)$ & 88.8 & $(78.9)$ \\
\hline $4^{\prime}$ & & & 72.0 & $(68.8)$ & 70.0 & (68.9) & $72.1^{g}$ & 7) $(68.1)$ & & & 72.0 & (68.9) & 70.0 & $(68.8)$ \\
\hline $5^{\prime}$ & & & 78.2 & $(72.1)$ & 77.9 & $(73.4)$ & 76.6 & (73.3) & & & 78.0 & $(72.0)$ & 77.7 & $(73.6)$ \\
\hline $6^{\prime}$ & & & 62.9 & $(62.0)$ & 62.6 & $(62.2)$ & 70.4 & $(69.4)$ & & & 63.0 & $(62.1)$ & 62.7 & $(62.2)$ \\
\hline $1^{\prime \prime}$ & & & d) & & 105.5( & (101.1) & 104.8( & $100.8)$ & & & d) & & 105.0 & (101.1) \\
\hline $2^{\prime \prime}$ & & & & & 75.4 & $(71.5)^{g)}$ & 75.3 & $(71.8)$ & & & & & 75.4 & $(71.6)$ \\
\hline $3^{\prime \prime}$ & & & & & 78.4 & $(73.4)$ & 78.7 & $(73.3)$ & & & & & 78.4 & $(73.4)$ \\
\hline $4^{\prime \prime}$ & & & & & 71.9 & $(68.9)$ & $71.9^{9}$ & 7) $(69.0)$ & & & & & 72.0 & $(68.8)$ \\
\hline $5^{\prime \prime}$ & & & & & 78.2 & $(72.1)$ & 78.0 & $(72.2)$ & & & & & 78.2 & $(72.0)$ \\
\hline \multirow[t]{2}{*}{$6^{\prime \prime}$} & & & & & 62.8 & $(62.2)$ & 63.0 & $(62.2)$ & & & & & 62.8 & $(62.2)$ \\
\hline & & & & & e) & & $f)$ & & & & & & e) & \\
\hline
\end{tabular}

a) ${ }^{1} \mathrm{H}$ NMR spectra were taken with a Varian $\mathrm{HA}-100$ and an A-60A spectrometer: $\delta_{\mathrm{H}} \pm 0.02$. ${ }^{13} \mathrm{C}$ NMR spectra were recorded on a Varian NV-14 FT NMR spectrometer at $15.087 \mathrm{MHz}$ using TMS as an internal reference $\left(\delta_{\mathrm{C}} 0\right)$ in 8 -mm spinning tubes at elevated temperatures: $\delta_{\mathrm{C}} \pm 0.1$.

b) Data on $\delta_{\mathrm{H}}$ for $\mathrm{H}-12$ (t), $\mathrm{H}-16 \beta$ (d), $\mathrm{H}-29$ and 30 , and $\mathrm{CO}_{2} \mathrm{Me}$ are 5.56 (5.41), $4.98(5.66), 1.09(0.99)$ and $1.00(0.93)$, and 3.67 (3.63), respectively, within \pm 0.02 . Data on $\delta_{\mathrm{C}}$ for $\mathrm{C}-7-9, \mathrm{C}-11-22, \mathrm{C}-26-30$, and $\mathrm{CO}_{2} \mathrm{Me}$ are 33.5 (33.8), $40.3(39.9), 47.8(47.9), 24.2(23.6), 122.5(123.4), 144.7$ (142.4), 42.2 (39.7), $36.1(32.2), 74.4(76.2), 49.5(47.7), 41.6$ $(40.6), 47.0(46.2), 30.8(30.5), 36.0(35.2), 32.2(31.0), 17.3(16.9), 27.3(26.4), 177.7(176.0), 33.1(33.2), 24.8(24.3)$, and $51.6(52.1)$, respectively, within $\pm 0.2( \pm 0.5$ for $C-7,11$, and 12$)$.

c) Not determinable.

d) Data on $\delta_{\mathrm{c}}$ for $\mathrm{C}-1^{\prime}-\mathrm{C}-6^{\prime}$ of $\mathrm{Me} \beta-\mathrm{D} \cdot \mathrm{Glc}$ are $105.4,75.0,78.4,72.0,78.0$ and 63.0 .

e) Data on $\delta_{\mathrm{C}}$ for C-1'-C- $6^{\prime \prime}$ of Me $\beta$-Lam are $105.5,73.8,88.7,70.2,77.7,62.8,105.0,75.4,78.3,71.9,78.2$ and 62.8 .

f) Data on $\delta_{\mathrm{C}}$ for C-1'-C-6 of Me $\beta$-Gen are $\left.\left.\left.105.3,75.0,9778.3,72.1,{ }^{h}\right) 76.9,70.2,105.0,74.9,9\right) 78.3,71.9,{ }^{h}\right) 77.9$ and 63.1.

$g, h)$ These assignments may be reversed. 
Then, ${ }^{1} \mathrm{H}$-noise-decoupled ${ }^{13} \mathrm{C}$ FT NMR spectra of $1-7$ in pyridine- $d_{5}$ at $100^{\circ}$ and those of $1 \mathrm{a}-7$ in $\mathrm{CDCl}_{3}$ at $80^{\circ}$ were measured and compared with each other. The ${ }^{13} \mathrm{C}$ signals of 6 and 7, and 6a and 7a were assigned by using known data on a number of oleanene-type triterpenoids, ${ }^{3)}$ known chemical-shift rules, ${ }^{3)}$ various ${ }^{1} \mathrm{H}$-decoupling techniques, ${ }^{3)}$ and chemicalshift comparisons from compound to compound. Thus, we found that signal positions of the aglycone moieties of $\mathbf{1 - 5}$ and $\mathbf{1 a - 5 a}$ agree well with those of the corresponding aglycones ( 6 and 7 , and $\mathbf{6 a}$ and 7a) assumed above except for some signals resulting from the A-ring carbons (see Table II).

Features of ${ }^{13} \mathrm{C}$ signals due to the sugar moieties suggested that the sugar attached to 1 and 4 is glucose, and that those attached to 2,3 , and 5 are glucobioses. Therefore, the spectra of $1-5$ and $1 \mathbf{a}-5 \mathbf{a}$ were compared with those of methyl $\beta$-D-glucopyranoside and some methyl $\beta$-glucobiosides in pyridine- $d_{5}$ (see Table II), and their peracetates in $\mathrm{CDCl}_{3}$, respectively, showing that 1 and $\mathbf{4}$ have a 3-O- $\beta$-glucopyranosyl group, and that 2 and 5 are 3-O- $\beta$-laminaribiosides whereas 3 is a $3-\mathrm{O}-\beta$-gentiobioside. As seen from Table II, the glycosidation shifts ${ }^{4,5)}$ (i.e., signal shifts from aglycone and sugar to glycoside) and the acetylation shifts ${ }^{6}$. are in harmony with those expected by the rules. ${ }^{4-6)}$

At last, aglycones 6 and $\mathbf{7}$ and D-glucose composing 1-5 were chemically confirmed by acid hydrolyses.

Thus, we have determined the structures of prosapogenin methyl esters $\mathbf{1}-\mathbf{5}$ to be methyl esters of 3-O- $\beta$-D-glucopyranosyl-, $\left.{ }^{2}\right) 3-\mathrm{O}-\beta$-laminaribiosyl-, and $3-\mathrm{O}-\beta$-gentiobiosyl-platycodigenins, and 3-O- $\beta$-D-glucopyranosyl- and 3-O- $\beta$-laminaribiosyl-polygalacic acids, respectively.

Acknowledgements We thank Prof. K. Koizumi of Mukogawa Women's University for a sample of laminaribiose and Dr. K. Takeda of this laboratory for his helpful advice and encouragement, and wish to dedicate this paper to the memory of the late Dr. T. Kubota of this laboratory who commenced this study in 1967.

Shionogi Research Laboratory,

Shionogi and Co., Ltd.

Fukushima-ku, Osaka, 553, Japan

Received November 18,1977
HIROSHI ISHII

KAZUO TORI

TAKeHIKo TOZYo

YoHKO YOSHIMURA

3) K. Tori, S. Seo, A. Shimaoka, and Y. Tomita, Tetrahedron Lett., 1974, 4227; S. Seo, Y. Tomita, and K. Tori, ibid., 1975, 7; S. Seo, Y. Tomita, and K. Tori, J. Chem. Soc. Chem. Commun., 1975, 270, 954; K. Tori, Y. Yoshimura, S. Seo, K. Sakurawi, Y. Tomita, and H. Ishii, Tetrahedron Lett., 19.76, 4163; and references cited therein.

4) R. Kasai, M. Suzuo, J. Asakawa, and O. Tanaka, Tetrahedron Lett., 1977, 175; K. Tori, S. Seo, Y. Yoshimura, H. Arita, and Y. Tomita, ibid., 1977, 179.

5) K. Tori, S. Seo, Y. Yoshimura, M. Nakamura, Y. Tomita, and H. Ishii, Tetrahedron Lett., 1976, 4167; K. Tori, T.T. Thang, M. Sangaré, and G. Lukacs, ibid., 1977, 717; H. Ishii, S. Seo, K. Tori, T. Tozyo, and Y. Yoshimura, ibid., 1977, 1227.

16) As a leading reference, see Y. Terui, K. Tori, and N. Tsuji, Tetrahedron Lett., 1976, 621. 